\title{
Effects of Long-Term Low-Molecular-Weight Heparin on Fractures and Bone Density in Non-Pregnant Adults: A Systematic Review With Meta-Analysis
}

\author{
Olga Gajic-Veljanoski, MD,PhD', Chai W. Phua, MD², Prakesh S. Shah, MD,MSc ${ }^{3,4}$, \\ and Angela M. Cheung, $M D, P h D^{1,4,5}$
}

'Osteoporosis Program, University Health Network/Toronto Rehabilitation Institute/Mount Sinai Hospital, Toronto, Canada; ${ }^{2}$ Department of Medicine, Royal Victoria Hospital, Barrie, Canada; ${ }^{3}$ Department of Pediatrics, Mount Sinai Hospital, Toronto, Canada; ${ }^{4}$ Institute of Health Policy Management and Evaluation, University of Toronto, Toronto, Canada; ${ }^{5}$ Department of Medicine, University of Toronto, Toronto, Ontario, Canada.

BACKGROUND: Adults who require long-term anticoagulation with low-molecular-weight heparin (LMWH) such as cancer patients or the elderly may be at increased risk of fractures.

OBJECTIVE: To determine the effects of LMWH therapy of at least 3 months' duration on fractures and bone mineral density (BMD) in non-pregnant adult populations.

METHODS: We systematically reviewed electronic databases (e.g., MEDLINE, EMBASE), conferences and bibliographies until June 2015 and included comparative studies in non-pregnant adult populations that examined the effects of LMWH ( $\geq 3$ months) on fractures and BMD. We synthesized evidence qualitatively and used random-effects meta-analysis to quantify the effect of LMWH on fractures. RESULTS: Sixteen articles reporting 14 studies were included: 10 clinical trials ( $n=4865$ participants) and four observational cohort studies ( 3 prospective, $\mathrm{n}=221$; 1 retrospective, $n=30$ ). BMD and fractures were secondary outcomes in the majority of trials, while they were primary outcomes in the majority of observational studies. In participants with venous thromboembolism and underlying cardiovascular disease or cancer (5 RCTs, $n=2280$ ), LMWH for 3-6 months did not increase the relative risk of all fractures at 6-12 months compared to unfractionated heparin, oral vitamin $\mathrm{K}$ antagonists or placebo [pooled risk ratio $(\mathrm{RR})=0.58,95 \% \mathrm{CI}$ : $0.23-1.43$; $\left.\mathrm{I}^{2}=12.5 \%\right]$. No statistically significant increase in the risk of fractures at 6-12 months was found for cancer patients $\left(\mathrm{RR}=1.08,95 \% \mathrm{CI}: 0.31-3.75 ; \mathrm{I}^{2}=4.4 \%\right)$. Based on the data from two prospective cohort studies $(n=166), \mathrm{LMWH}$ for 3-24 months decreased mean BMD by 2.8-4.8\% (depending on the BMD site) compared to mean BMD decreases of 1.2-2.5\% with oral vitamin $\mathrm{K}$ antagonists. CONCLUSIONS: LMWH for 3-6 months may not increase the risk of fractures, but longer exposure for up to 24 months may adversely affect BMD. Clinicians should consider monitoring BMD in adults on long-term LMWH who are at increased risk of bone loss or fracture.

Electronic supplementary material The online version of this article (doi:10.1007/s11606-016-3603-8) contains supplementary material, which is available to authorized users.

Received June 30, 2015

Revised November 11, 2015

Accepted January 21, 2016

Published online February 19, 2016
KEY WORDS: heparin, low-molecular-weight; fractures; bone; bone density; systematic review.

J Gen Intern Med 31(8):947-57

DOI: $10.1007 / \mathrm{s} 11606-016-3603-8$

๑) Society of General Internal Medicine 2016

\section{INTRODUCTION}

Low-molecular-weight heparin (LMWH) is recommended as a first-line agent for the primary and secondary prevention of venous thromboembolism (VTE). ${ }^{1-7}$ Extended or long-term therapy with LMWH is indicated in patients who are unable to safely take or tolerate other oral anticoagulants ${ }^{2,6-11}$ and in cancer patients, as long-term LMWH has demonstrated superiority for reduction in VTE recurrence and mortality. ${ }^{12-14}$

Studies assessing the safety of long-term LMWH against oral vitamin $\mathrm{K}$ antagonists (VKAs) or novel anticoagulants in cancer or other populations were designed to address more common side effects: the risk of bleeding and thrombocytopenia. ${ }^{15-28}$ The adverse effects of long-term LMWH on bone in terms of increased risks of fractures (i.e., clinically most important but rare outcomes) and bone loss are less commonly researched and unclear. The effects of LMWH on bone were mainly studied in the pregnant population. Some research has suggested that long-term LMWH prophylaxis in pregnancy for at least 3 months was associated with bone loss and fractures, ${ }^{29-31}$ although others have argued that the absolute risk of fracture in this population was small $(1-2 \%)^{32}$ and that decreases in mean bone mineral density (BMD) of $2-4 \%$ caused by the prophylactic doses of LMWH or unfractionated heparin (UFH) were similar to the bone loss that occurs physiologically during pregnancy. ${ }^{33,34}$ Nevertheless, a decrease in BMD of $2-4 \%$ or a small increase in the risk of fracture of up to $2 \%$ would be clinically important for other adult populations such as cancer patients or the elderly who may require long-term LMWH and whose baseline risk of fractures is increased owing to aging or underlying comorbidities. ${ }^{35-37}$ Therefore, we reviewed the literature in non-pregnant adult populations to determine the effects of long-term (at least 3 months') use of LMWH on fractures and BMD. 


\section{METHODS}

\section{Search Strategy and Study Selection}

This study follows the Preferred Reporting Items for Systematic Reviews and Meta-analyses (PRISMA) guidelines for the conduct and reporting of systematic reviews (online Appendices). ${ }^{38}$ We systematically searched electronic databases (MEDLINE, EMBASE, the Cochrane Library and Cochrane Controlled Clinical Trials Register from their inception through June 2015), proceedings from annual meetings and bibliographies (online Appendices 1 and 2). We included English-language clinical trials and observational studies (retrospective and prospective cohort and case-control studies) in non-pregnant adults (age $>18$ years) that assessed the effects of long-term LMWH treatment (for at least 3 months) on fractures or BMD. We excluded reviews, letters or commentaries (without original data), descriptive (case series/reports) or cross-sectional observational studies, studies that did not report bone outcomes, reported short-term exposure to LMWH or long-term exposure to UFH only or included pregnant participants. One reviewer (OGV) assessed the titles and abstracts of all retrieved citations. Full texts of potentially relevant studies were reviewed by two independent reviewers (OGV, PSS).

\section{Data Extraction and Methodological Quality Assessment}

Two reviewers (OGV and $\mathrm{CP}$ ) extracted data on the number of all reported fractures and absolute or relative changes in BMD as measured by dual-energy X-ray absorptiometry (DXA). At least two reviewers (OGV, CP and PSS) independently assessed the methodological quality of the included studies using previously validated quality assessment checklists (online Appendix 1). ${ }^{39,40}$ Disagreements were discussed among the three reviewers and were resolved by consensus (the initial inter-rater agreement was high but was not statistically evaluated using the kappa statistic). Clinical trials were appraised by an 11-item tool developed by the Cochrane Collaboration Back Review Group, and observational studies were appraised by the Newcastle Ottawa Scale-NOS (9 items). ${ }^{39,40}$ To evaluate bone outcomes, we a priori defined quality criteria specific to osteoporosis research and added six new items to the clinical trial checklist and two new items to the NOS.

\section{Qualitative and Quantitative Syntheses}

We qualitatively synthesized the findings of all studies. We combined clinical trials reporting fractures using the MantelHaenszel random-effects method of meta-analysis. ${ }^{41-43}$ Two $a$ priori defined subgroup meta-analyses were performed: one in trials including cancer patients only and one in trials using VKA as comparator. We estimated the pooled relative risk (RR) and pooled risk difference (RD) with the corresponding $95 \%$ confidence intervals $(95 \% \mathrm{CI}) . \mathrm{I}^{2}$ statistic values were used to quantify statistical heterogeneity beyond chance. ${ }^{44}$ As the number of trials was small $(>10)$, a funnel plot was not used to assess publication bias. ${ }^{41,45}$ All tests of significance were two-sided with statistical significance defined at $\mathrm{p}<0.05$ for overall effect and $<0.1$ for heterogeneity. Meta-analyses were done using R 2.13.1 (R Foundation for Statistical Computing, Vienna, Austria, 2008).

\section{RESULTS}

\section{Search and Study Selection}

Of 3098 identified and screened records through searches of electronic databases and bibliographies, 16 articles were included (one was reported as an abstract, ${ }^{46}$; Fig. 1). Eleven citations ${ }^{46-56}$ described ten clinical trials. The other five publications were observational cohort studies. ${ }^{57-61}$ Two citations described the same study, one presented the results for a shorter 12-month duration, ${ }^{60}$ and the second presented the results for a longer 24-month follow-up. ${ }^{61}$ Thus, a total of ten clinical trials and four observational studies were included in this review.

\section{Study Characteristics}

Of the 10 clinical trials, including 4865 participants, 1 was a cross-over trial, ${ }^{53}$ while the rest were parallel-group randomized controlled clinical trials (RCTs) (Table 1). Of the 4 cohort

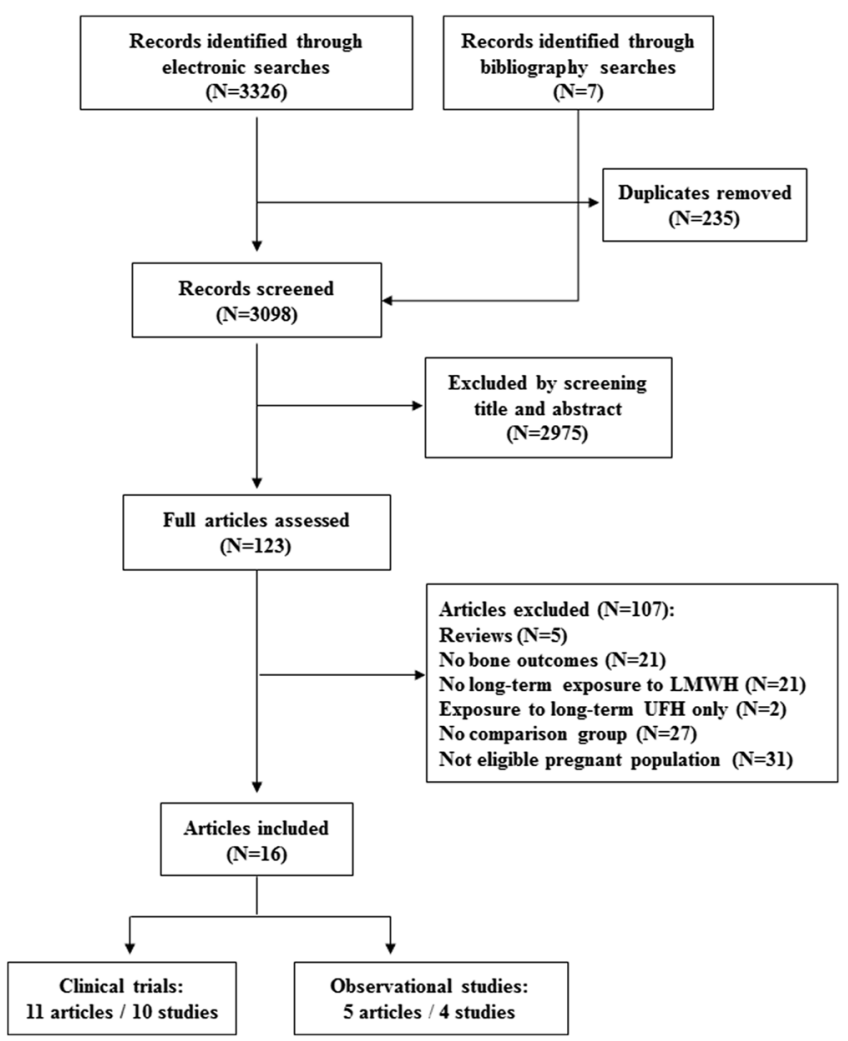

Figure 1. PRISMA flow diagram; n denotes the total number of citations. LMWH denotes low-molecular-weight heparin; UFH denotes unfractionated heparin. 


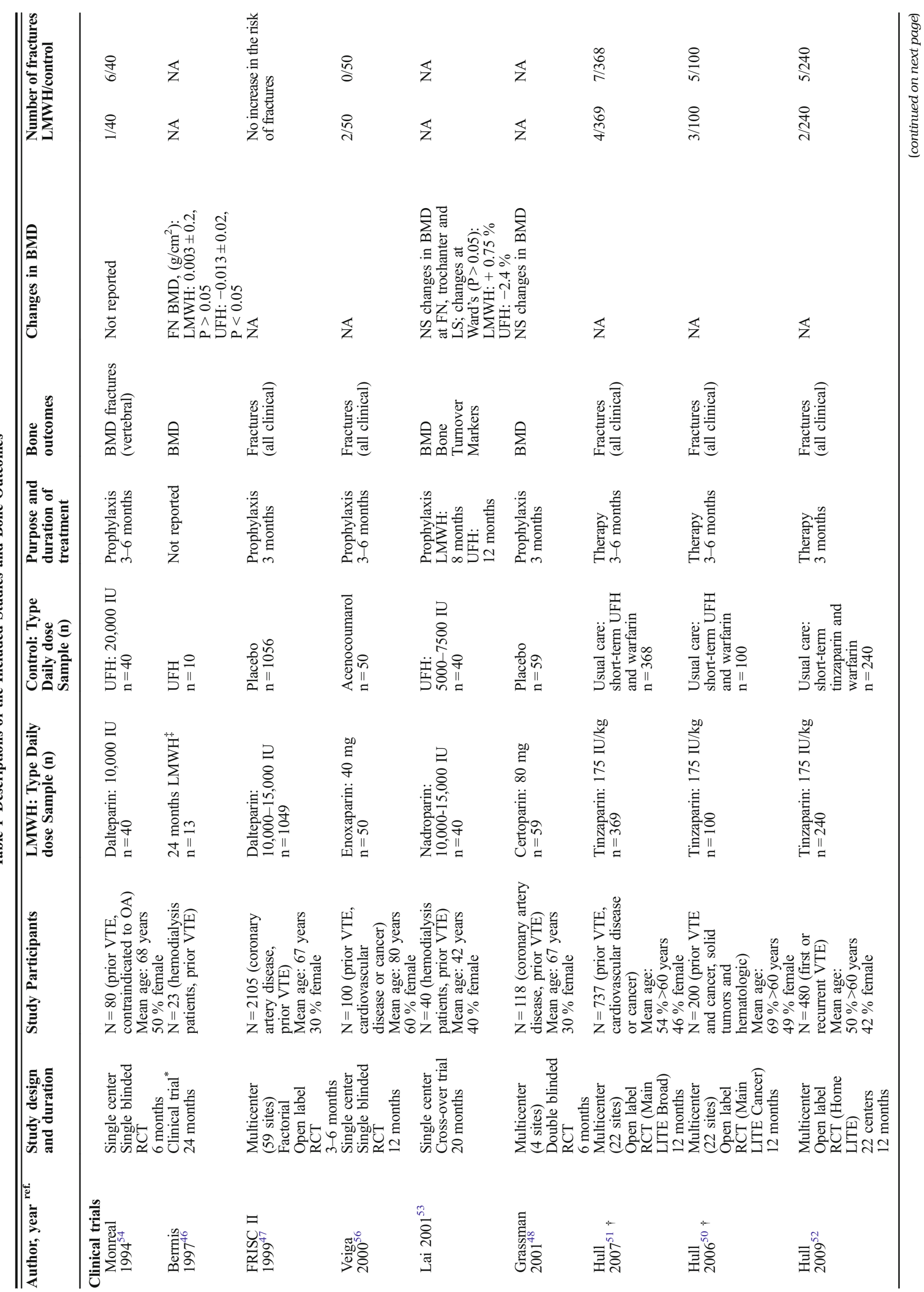




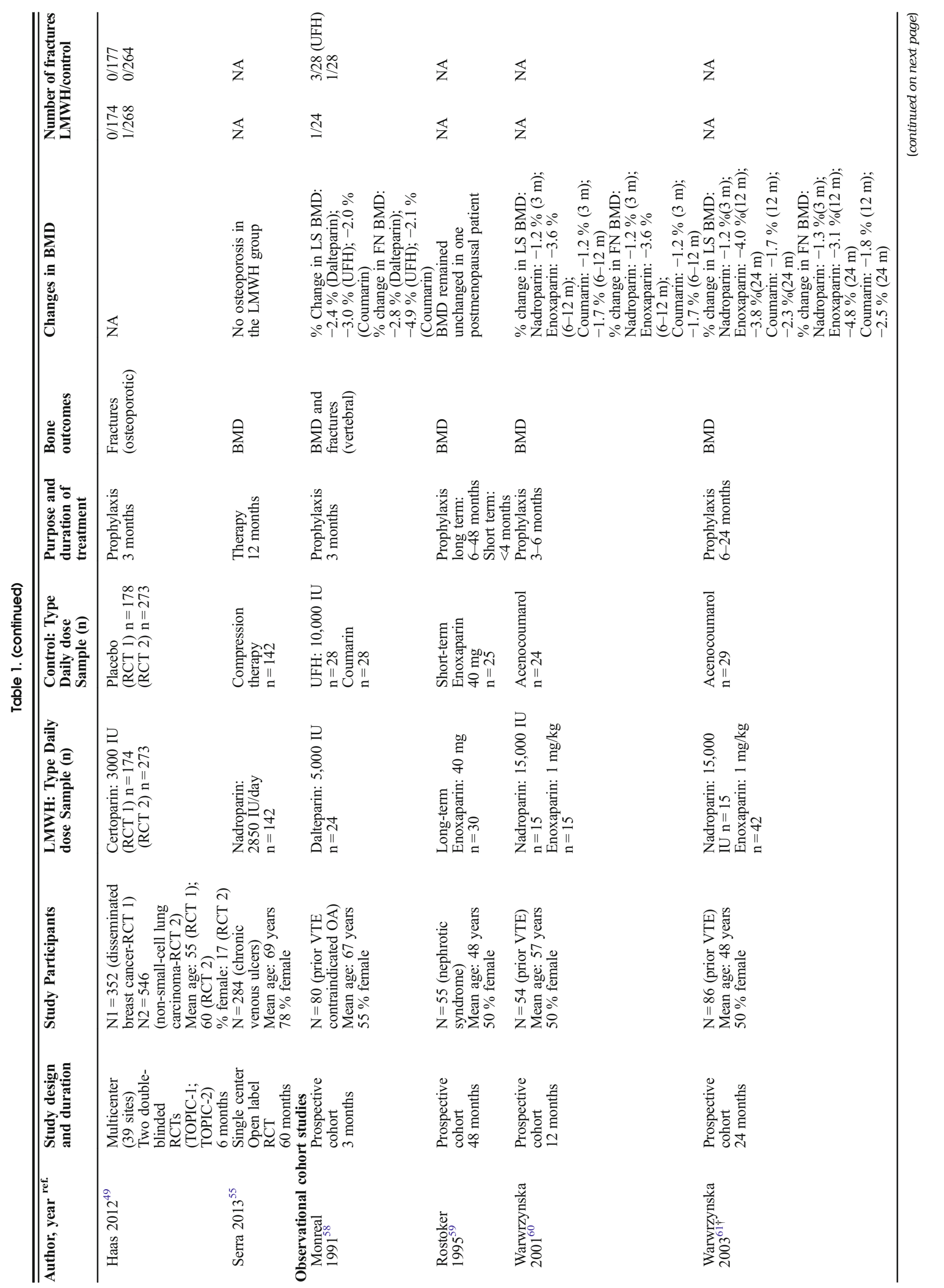


studies of 251 participants, ${ }^{57-61} 3 \mathrm{had}$ a prospective design (221 participants) ${ }^{58-61}$ (Table 1).

The majority of the trial participants were older than 60 years, male and had a prior VTE resulting from underlying cardiovascular, renal or malignant diseases. Three studies included cancer patients with solid or hematologic malignancies and with disseminated breast cancer or inoperable nonsmall-cell lung carcinoma. ${ }^{49,50,56}$ Compared to the age and sex of the trial participants, the mean age of the cohort study participants was younger and more heterogeneous (30 to 67 years) with three studies including $50 \%$ or more females (Table 1). Long-term LMWH was compared to long-term UFH in three trials and one cohort study, ${ }^{46,53,54,58}$ to VKA in three trials ${ }^{51,52,56}$ and two cohort studies, ${ }^{58,61}$ to short-term LMWH in one cohort study, ${ }^{59}$ compression therapy in one trial, ${ }^{55}$ placebo in three trials ${ }^{47-49}$ and no treatment in a cohort study. ${ }^{57}$ Various preparations of LMWH (dalteparin, enoxaparin, nadroparin, certoparin and tinzaparin) were used for the purpose of prophylaxis (six trials ${ }^{47-49,53,54,56}$ and all cohort studies) or therapy (three trials ${ }^{50-52,55}$ ). The duration of LMWH treatment was between 3 and 24 months in all but one cohort study ${ }^{59}$ that compared long- to short-term treatment with LMWH (6-48 months vs. $<4$ months).

\section{Methodological quality}

The overall methodological quality of the included studies was limited (Tables 2 and 3). Two RCTs ${ }^{47,49}$ adequately described the generation of the randomization sequence, concealment of the allocation and blinding, and one $\mathrm{RCT}^{47}$ also adequately addressed incomplete data (Table 2). Most trials did not fulfill the six additional criteria specific to osteoporosis. Calcium and vitamin D dietary intakes, physical activity/immobility/bed rest, prior fractures or history of osteoporosis were not assessed. Timing of BMD or fracture assessment was not different between the groups. One cross-over trial examined BMD as the primary outcome, ${ }^{53}$ while in four other $\mathrm{RCTs}^{46,48,54,55}$ information regarding changes in BMD was limited. In the RCTs, ${ }^{47,49-52,54,56}$ fractures were assessed among secondary outcomes, with samples ranging between $80^{54}$ to 883 subjects. ${ }^{49}$ Observational studies were small in size $\left(30^{57}\right.$ to $\left.86^{61}\right)$, but they assessed BMD and/or fractures as primary outcomes (Table 3). All were hospital-based cohort studies, and the majority did not clearly describe loss to follow-up or did not report and adjust for important confounders.

\section{Fractures}

Fractures were reported in 8 publications, ${ }^{47,49-52,54,56,58}$ 7 describing 6 trials of 4320 participants and 1 describing a prospective cohort study of 80 participants $^{58}$ (Table 1). We pooled data of the five trials including 2280 participants with VTE and underlying cardiovascular disease and cancer. ${ }^{49,51,52,54,56}$ We excluded the FRISC II study (2015 participants) that reported no 
Table 2 Methodological Quality of the Ten Included Clinical Trials

\begin{tabular}{|c|c|c|c|c|c|c|c|c|c|c|}
\hline Study quality criteria & $\begin{array}{l}\text { Monreal } \\
1994^{54}\end{array}$ & $\begin{array}{l}\text { Bernis } \\
1997^{46^{*}}\end{array}$ & $\begin{array}{l}\text { FRISC } \\
\text { II } 1999^{47}\end{array}$ & $\begin{array}{l}\text { Veiga } \\
2000^{56}\end{array}$ & $\operatorname{Lai}_{2001^{53}}$ & $\begin{array}{l}\text { Grassman } \\
2001^{48}\end{array}$ & $\begin{array}{l}\text { Hull } \\
2007^{50,51 \dagger}\end{array}$ & $\begin{array}{l}\text { Hull } \\
2009^{52}\end{array}$ & $\begin{array}{l}\text { Haas } \\
2012^{49}\end{array}$ & $\begin{array}{l}\text { Serra } \\
2013^{55}\end{array}$ \\
\hline Adequate randomization & Yes & Unclear & Yes & Yes & No & Unclear & Yes & Yes & Yes & Unclear \\
\hline Concealed allocation & Unclear & Unclear & Yes & Yes & No & Yes & Yes & Yes & Yes & No \\
\hline $\begin{array}{l}\text { Prognostic factor } \\
\text { balance at baseline for } \\
\text { the primary disease }\end{array}$ & Yes & Unclear & Yes & No & No & Yes & No & No & No & No \\
\hline Blinding of participants & No & Unclear & Yes & No & Yes & Yes & No & No & Yes & No \\
\hline $\begin{array}{l}\text { Blinding of healthcare } \\
\text { providers }\end{array}$ & Yes & Unclear & Yes & No & No & Yes & No & No & Yes & No \\
\hline $\begin{array}{l}\text { Blinding of outcome } \\
\text { assessor }\end{array}$ & Yes & Unclear & Yes & Yes & No & Unclear & No & No & Yes & No \\
\hline Co-intervention similar & Yes & Unclear & Yes & Yes & Yes & Unclear & Yes & Yes & Yes & Yes \\
\hline $\begin{array}{l}\text { Acceptable compliance } \\
\text { in both groups }\end{array}$ & Unclear & Unclear & Unclear & Yes & Yes & Unclear & Unclear & Unclear & Unclear & Unclear \\
\hline $\begin{array}{l}\text { Drop-out rate described } \\
\text { and acceptable }(<10 \%)\end{array}$ & Yes & Unclear & Yes & Yes & No & No & Yes & Yes & Yes & Yes \\
\hline $\begin{array}{l}\text { Comparable timing of } \\
\text { the primary outcome } \\
\text { assessment in both } \\
\text { groups }\end{array}$ & Yes & Unclear & Yes & Yes & Yes & Yes & Yes & Yes & Yes & Yes \\
\hline $\begin{array}{l}\text { Intention to treat } \\
\text { analysis }\end{array}$ & Yes & Unclear & Yes & Yes & No & Unclear & Yes & Yes & No & Yes \\
\hline $\begin{array}{l}\text { Van Tulder internal } \\
\text { validity score }\end{array}$ & $8 / 11$ & NA & $10 / 11$ & $8 / 11$ & $4 / 11$ & $5 / 11$ & $6 / 11$ & $6 / 11$ & $8 / 11$ & $4 / 11$ \\
\hline $\begin{array}{l}\text { Additional criterion 1: } \\
\text { prognostic factor } \\
\text { balance at baseline for } \\
\text { osteoporosis }\end{array}$ & Yes & Unclear & Unclear & Unclear & Yes & Yes & No & Unclear & No & Unclear \\
\hline $\begin{array}{l}\text { Additional criterion 2: } \\
\text { contamination, use of } \\
\text { heparin in both } \\
\text { intervention groups }\end{array}$ & No & Unclear & No & No & No & No & No & Yes & No & No \\
\hline $\begin{array}{l}\text { Additional criterion } 3 \text { : } \\
\text { comparable timing of } \\
\text { bone outcome } \\
\text { assessment in both } \\
\text { groups }\end{array}$ & Yes & Unclear & Unclear & Yes & Yes & Yes & Yes & Yes & Yes & Unclear \\
\hline $\begin{array}{l}\text { Additional criterion } 4 \text { : } \\
\text { if fracture was assessed } \\
\text { among adverse events, } \\
\text { was duration of follow-up } \\
\text { to detect a fracture } \\
\text { adequate ( } \geq 1 \text { year) }\end{array}$ & No & Unclear & No & Yes & NA & NA & Yes & Yes & No & NA \\
\hline $\begin{array}{l}\text { Additional criterion 5: } \\
\text { sample large enough to } \\
\text { detect differences between } \\
\text { the groups regarding } \\
\text { fracture } \\
\text { outcome }\end{array}$ & No & Unclear & Yes & No & No & No & No & No & No & No \\
\hline $\begin{array}{l}\text { Additional criterion } 6 \text { : bone } \\
\text { outcomes assessed as } \\
\text { secondary }\end{array}$ & Yes & Unclear & Yes & Yes & No & Yes & Yes & Yes & Yes & Yes \\
\hline
\end{tabular}

*Study by Bernis et al. ${ }^{46}$ was reported as abstract and was rated unclear; ${ }^{*}$ two published articles ${ }^{50,51}$ represent the data of the same study.

increase in the risk of fractures after 6 months of prophylaxis with dalterparin as the corresponding author could not provide the individual group fracture data. ${ }^{47}$

In a 3-month prospective cohort study ${ }^{58}$ of 80 participants with recurrent VTE (28 to 91 years), fractures occurred more frequently with UFH $(20,000 \mathrm{IU} /$ day $)$ than with dalterparin (10,000 IU/day) or coumarin (Table 1). In RCTs, fractures were more frequent in the control groups than in the LMWH group [UFH: $6 / 40(15 \%)$ vs. LMWH: $1 / 40(2.5 \%)^{54}$; VKA: $12 / 658(1.8 \%)$ vs. LMWH: $\left.8 / 659(1.2 \%)^{51,52,56}\right]$. In the LMWH groups per se, fractures were less frequent in the RCTs that used lower prophylactic doses of certoparin, dalteparin or enoxaparin ${ }^{49,54,56}$ than in those that used higher therapeutic doses of tinzaparin ${ }^{51,52}$ (4/532 vs. 6/609, 3-6 months of therapy).

Although patient populations were clinically heterogeneous in terms of underlying comorbidities (cardiovascular disease and cancer), the main and subgroup meta-analyses were associated with small statistical heterogeneity $\left(\mathrm{I}^{2}\right.$ statistic $<13 \%) .{ }^{44}$ In a random-effects meta-analysis (5 RCTs, 2280 participants), LMWH did not significantly increase the risk of all fractures compared to control [pooled RR: $0.58,95 \% \mathrm{CI}$ : $0.23,1.43(\mathrm{P}=0.24) ; \mathrm{I}^{2}=12.5 \%(\mathrm{P}=0.33)$, Fig. 2a]. A subgroup meta-analysis of the three RCTs in 1183 cancer patients ${ }^{49,50,56}$ suggested a comparable risk of fractures between the groups as well (pooled RR: 1.08, $95 \%$ CI:0.31, 3.75 
Table 3 Methodological Quality of the Four Observational Cohort Studies

\begin{tabular}{|c|c|c|c|c|}
\hline Study quality criteria & $\begin{array}{l}\text { Monreal } \\
1991^{58}\end{array}$ & $\begin{array}{l}\text { Rostoker } \\
1995^{59}\end{array}$ & $\begin{array}{l}\text { Wawrzynska } \\
2001 \& 2003^{60,61 *}\end{array}$ & $\begin{array}{l}\text { Grzegorzewska } \\
2008^{57}\end{array}$ \\
\hline \multicolumn{5}{|l|}{ Selection } \\
\hline Representativeness of the exposed cohort & - & - & - & - \\
\hline Selection of the non-exposed cohort & - & - & - & - \\
\hline Ascertainment of exposure & * & * & * & * \\
\hline $\begin{array}{l}\text { Demonstration that outcome of interest (i.e., bone outcome) } \\
\text { was not present at start of study }\end{array}$ & * & - & $*$ & - \\
\hline \multicolumn{5}{|l|}{ Comparability } \\
\hline $\begin{array}{l}\text { Comparability of cohorts on the basis of the design or } \\
\text { analysis }\end{array}$ & - & - & - & $* *$ \\
\hline \multicolumn{5}{|l|}{ Outcome (i.e., bone outcome) } \\
\hline Ascertainment of outcome & * & $*$ & * & * \\
\hline Follow-up long enough for outcomes to occur & * & $*$ & * & $*$ \\
\hline Adequacy of follow-up of cohorts & * & - & - & * \\
\hline NOS score & $5 / 9$ & $3 / 9$ & $4 / 9$ & $6 / 9$ \\
\hline $\begin{array}{l}\text { Additional criterion 1: large sample that provides sufficient } \\
\text { statistical power to detect differences between the groups } \\
\text { regarding fracture outcome }\end{array}$ & No & No & No & No \\
\hline Additional criterion 2: bone outcome assessed as secondary & No & Yes & No & No \\
\hline
\end{tabular}

*Two published articles ${ }^{60,61}$ done by the same authors were evaluated together; dash (-) denotes blank cell and no star; NOS = Newcastle Ottawa Scale

$(\mathrm{P}=0.90) ; \mathrm{I}^{2}=4.4 \%(\mathrm{P}=0.35)$, Fig. $\left.2 \mathrm{~b}\right]$. We also found no statistically significant change in the risk of fractures in a subgroup meta-analysis of the three RCTs (1317 participants $^{51,52,56}$ ) comparing LMWH to VKA [pooled RR: 0.64, $95 \%$ CI: $0.24,1.71(\mathrm{P}=0.37), \mathrm{I}^{2}=8 \%(\mathrm{P}=0.33)$, Fig. $\left.2 \mathrm{c}\right]$. The absolute risk difference of fractures was null in all analyses. Pooled risk difference was 0.00 [95 \% CI: $-0.02,0.01$ $(\mathrm{P}=0.62)]$ in the meta-analysis of all five RCTs and in the subgroup meta-analysis of the RCTs in cancer patients only [95 \% CI: $-0.004,0.01(\mathrm{P}=0.46)]$. In the meta-analysis of trials using VKA as control, it was -0.01 [95\% CI: -0.02 , $0.01(\mathrm{P}=0.34)]$. The number of included studies was small; thus, it was difficult to make inferences regarding publication bias.

\section{Changes in BMD}

BMD was assessed by DXA in 5 clinical trials including 545 participants ${ }^{46,48,53-55}$ and in all cohort studies including 251 participants (Table 1). Due to low quality in reporting of BMD data, we did not conduct a meta-analysis. Qualitative synthesis of the results is included below.

Of the five clinical trials that assessed BMD, two trials ${ }^{48,55}$ provided statements regarding the absence of bone loss and one $\mathrm{RCT}^{54}$ did not report the data. The other two trials ${ }^{46,53}$ found small or insignificant changes in mean BMD (Table 1). A crossover trial ${ }^{53}$ in 40 stable hemodialysis patients showed no important changes in mean BMD at the lumbar spine, femoral neck or total hip; changes at Ward's triangle of $-1.6 \%$ after the first 8 months of UFH and of $+0.7 \%$ after another 8 months of LWMH were within the range of test variation $(P>0.05)$. In a parallel-group clinical trial ${ }^{46}$ in 23 hemodialysis patients, UFH for 24 months decreased the mean BMD at the femoral neck $\left(-0.013 \mathrm{~g} / \mathrm{cm}^{2}, \mathrm{P}<0.05\right)$, while LMWH did not have any significant change $\left(0.0003 \mathrm{~g} / \mathrm{cm}^{2}, \mathrm{P}>0.05\right)$.
BMD was assessed as the primary outcome in three of the four cohort studies (Table 1). In contrast to the clinical trials, they found a larger decrease in mean BMD with long-term LMWH treatment. A retrospective cohort study in adult uremic dialysis patients ${ }^{57}$ showed that LMWH use was associated with statistically significant decreases in mean BMD at the femoral neck $\left[0.71 \pm 0.10 \mathrm{~g} / \mathrm{cm}^{2}(\mathrm{LMWH})\right.$ vs. $0.90 \pm 0.12 \mathrm{~g} /$ $\mathrm{cm}^{2}$ (no treatment), $\left.\mathrm{P}=0.000\right]$. In a prospective cohort study ${ }^{58}$ of 80 participants, a $2.4 \%$ decrease in mean BMD at the lumbar spine and a $2.8 \%$ decrease at the femoral neck were identified after 3 months of prophylaxis with LMWH; the corresponding decreases of $2.0 \%$ and $2.1 \%$ were shown for VKA and $3.0 \%$ and $4.9 \%$ for UFH . Another prospective study of 86 participants ${ }^{61}$ reported statistically significant differences in mean BMD between the enoxaparin and coumarin groups $(\mathrm{P}<0.005)$. Twenty-four months of prophylaxis with enoxaparin was associated with a decrease in mean BMD of $3.8 \%$ and $4.8 \%$ at the lumbar spine and femoral neck, respectively, compared to the corresponding $2.3 \%$ and $2.5 \%$ decreases with VKA.

\section{DISCUSSION}

This systematic review in adult non-pregnant populations with VTE, cancer and other underlying comorbidities found that long-term LMWH therapy reduced mean BMD from 1.2$2.8 \%$ to $4.8 \%$ after 3 to 24 months of use in two prospective observational studies of VTE prophylaxis with LMWH, while no significant changes were found in five clinical trials. Our meta-analysis did not find an increase in fracture risk with LMWH when compared to controls where the control groups were taking mainly UFH or VKA. Based on the current literature, LMWH does not seem to have a strong detrimental effect on bone. However, the potential for a greater than $3 \%$ 


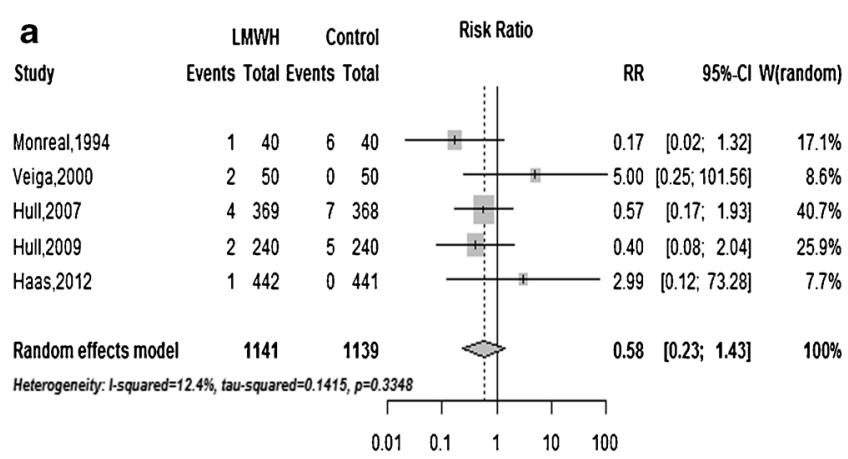

b

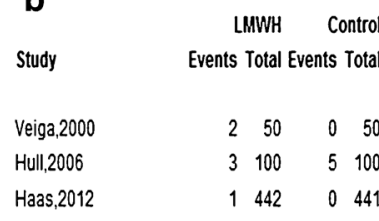

Risk Ratio

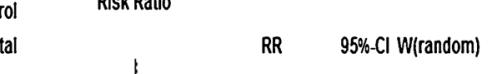

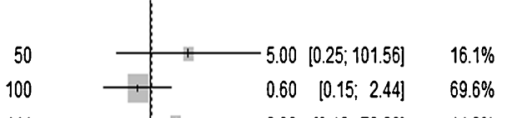

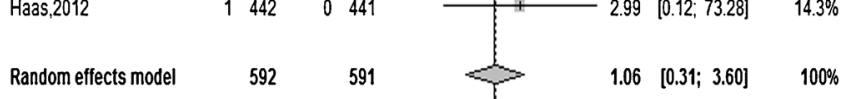
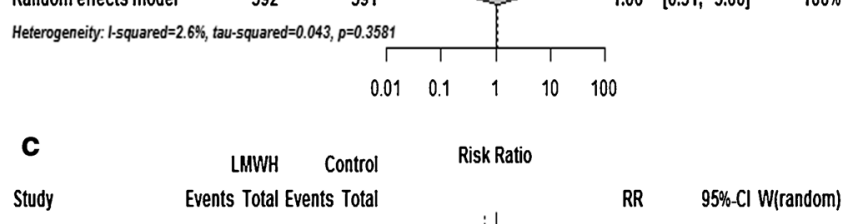

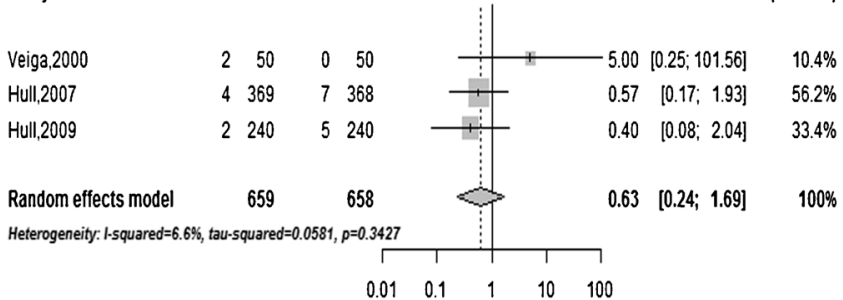

Figure 2. a Forest plot: The effect of long-term low-molecularweight heparin vs. control on all fractures in non-pregnant participants. LMWH denotes low-molecular-weight heparin. Control: unfractionated heparin, oral vitamin $K$ antagonist or placebo; $R R$ denotes risk ratio; $R R<1$ favors $L M W H ; R R>1$ favors control treatment. b Forest plot: Long-term low-molecular-weight heparin vs. control in cancer patients. LMWH denotes low-molecular-weight heparin. Control: oral vitamin $\mathrm{K}$ antagonist or placebo; $R R$ denotes risk ratio; $R R<1$ favors $L M W H ; R R>1$ favors control treatment. c

Forest plot: Long-term low-molecular- weight heparin vs. oral

vitamin $K$ antagonists in non-pregnant participants. LMWH

denotes low-molecular-weight heparin. Control: oral vitamin $\mathbf{K}$ antagonists (i.e., acenocoumarol/warfarin); RR denotes risk ratio; RR $<1$ favors LMWH; RR >1 favors control treatment.

decrease in BMD may be clinically important in some adult populations on LMWH as a prior study (the FLEX trial-a trial of alendronate discontinuation) showed that bone loss of greater than $3 \%$ over 2 years was associated with a 1.68 -times increased risk of fractures (95\% CI: 1.05-2.72). ${ }^{62}$

Currently, LMWH is not recognized as a major modifying factor for fractures in standardized fracture risk assessment tools such as FRAX or CAROC. ${ }^{63,64}$ Using the FRAX 10-year fracture risk assessment tool, ${ }^{65,66}$ one can show that if LMWH were to induce a bone loss of $4.8 \%$ over 2 years in a 68 -year-old male patient $[\mathrm{BMI}=26 \mathrm{~kg} /$ $\mathrm{cm}^{2}$; baseline BMD T-score $=-2.0$ corresponding to mean BMD $($ femoral neck $)=0.620 \mathrm{~g} / \mathrm{cm}^{2}$ ], the 10 -year probability of a major osteoporotic fracture would increase by

$2.1 \%$ (from baseline $7.9 \%$ to $10 \%$ ) and that of a hip fracture by $1.8 \%$ (from $2.2 \%$ to $4.0 \%$ ), ${ }^{67}$ making the patient potentially eligible for pharmacologic treatment. ${ }^{63}$ Thus, it is important for clinicians to make sure adults on long-term LMWH get adequate calcium and vitamin $\mathrm{D}$ to minimize bone loss and to consider monitoring BMD in those who are at increased risk of bone loss or fractures.

\section{Strengths and Weaknesses}

Our systematic review included a comprehensive search strategy that combined searches of electronic databases, conference proceedings and manual searches of bibliographies. ${ }^{68,69}$ This minimized the chance of omitting relevant information regarding the two bone outcomes that were not reported in the abstracts but in the text or tables. We abstracted the fracture and BMD data and conducted quality assessments in duplicate to minimize error due to chance and bias. To reduce the chance of false conclusions, we conducted quantitative and qualitative evidence syntheses. ${ }^{38}$ However, the majority of studies included in this review had high risk of bias; thus, the overall level of evidence is limited.

Fractures were collected as secondary outcomes, and their assessment was variable among the studies. The small number of studies, small study populations and short duration of follow-up (up to 1 year) (especially for rare fracture outcomes that occurred in less than $1 \%$ in the VKA and placebo groups) had an impact on the statistical power of our analyses. Also, overall fracture incidence following long-term LMWH treatment may be underestimated. This is because only one trial ${ }^{54}$ captured clinical vertebral fractures, as measured by plain radiographs in participants who complained of back pain. Vertebral fractures are the most common type of osteoporotic fractures, ${ }^{70}$ but the majority occur asymptomatically and only one-third is clinically recognized. ${ }^{71}$

The lack of an effect of LMWH on BMD was apparent in the clinical trials as opposed to observational cohort studies. However, the observational studies examined bone outcomes as their primary endpoints. Although selection bias and confounding can be better controlled through allocation concealment and randomization in $\mathrm{RCTs}^{72}$ the majority of the reviewed trials examined BMD and/or fractures as secondary end points and were adequately powered for their primary efficacy end points. In this review, BMD was the primary outcome in one cross-over trial only. ${ }^{53}$ Also, the study populations were similar in terms of their indication for long-term LMWH, but some of these populations such as hemodialysis or cancer patients can have a higher baseline risk of osteoporosis owing to their underlying diseases or treatments. ${ }^{35-37}$ Given the various methodological limitations of the cohort studies (selection bias, confounding, small samples, inadequate ascertainment of outcomes), the effect of LMWH on BMD can be distorted in either direction. ${ }^{72,73}$ Thus, we qualitatively synthesized the BMD 
data to express lack of confidence in the precision and magnitude of bone loss with LMWH.

In addition, control treatments in the studies were not consistent and included UFH, VKA or placebo. Previous research has suggested that UFH and VKA increase the risk of bone loss and fractures. For example, animal models suggest that UFH adversely affects bone metabolism as it accelerates bone resorption and suppresses bone formation. ${ }^{74,75}$ Warfarin use was also shown to increase both bone loss and risk of vertebral fractures in some studies in women. ${ }^{76,77}$ The potential adverse effects of LMWH on bone may be portrayed to be less when the comparator group has an increased likelihood for developing such adverse events. In light of our findings of a statistically nonsignificant increase in the risk of fractures between the groups [LMWH vs. control (UFH, VKA or placebo): $\mathrm{RR}=0.58,95$ $\%$ CI: $0.23-1.43$; LMWH vs. VKA: RR $=0.64,95 \%$ CI: 0.24 1.71], one interpretation could be that long-term LMWH treatment poses a similar risk of fractures as UFH or VKA-a conclusion that needs further confirmation in large welldesigned prospective studies.

Some animal studies have suggested a dose-dependent effect of LMWH on bone, ${ }^{78,79}$ but this relationship has not been fully explored or confirmed in humans. Qualitative analysis of the data suggests a slight trend towards dose-dependent effects of LMWH on bone. In the prophylactic-dose LMWH groups (using certoparin, dalteparin or enoxaparin), $0.75 \%$ of participants had fractures compared to $0.99 \%$ in the higher therapeutic-dosing groups (using tinzaparin). However, both the numbers of fractures and sizes of the RCTs are small, and the observed difference could be due to chance alone. More importantly, patients requiring larger therapeutic doses are likely at different baseline risks for fractures compared to those who only require prophylactic doses. Also, it remains unclear whether various preparations of LMWH exert different effects on bone. Some authors suggest that the preparations of LMWH can be considered a family of closely related drugs (i.e., class effect) despite their in vitro differences. ${ }^{80}$ Our analysis also suggests that the amount of LMWH may be more important than the LMWH preparation. Consequently, future studies need to explore whether there is a threshold effect with LMWH when it comes to the dose and duration of LMWH treatment.

\section{Evidence from Other Studies}

Few studies have systematically examined the risk of fractures with long-term LMWH therapy in non-pregnant adults. ${ }^{31}$ To our knowledge, three reviews systematically evaluated bone complications of long-term LMWH treatment in pregnant participants prone to VTE. ${ }^{29-31}$ Ensom et al. ${ }^{29}$ reviewed 40 studies associated with long-term LMWH use in over 700 pregnant women and found two cases of osteoporotic vertebral fractures. Greer et al. ${ }^{30}$ identified 64 eligible studies in 2777 pregnancies comparing long-term LMWH against control treatments and found one study reporting one vertebral fracture (rate: $0.04 \%$ ) in a woman treated with high-dose LMWH $(15,000 \mathrm{IU} /$ day) for 9 months. The authors warned about other cases of osteoporotic fractures in this population and urged further research concerning LMWH-induced osteoporosis. Lefkou et al., ${ }^{31}$ who qualitatively synthesized the literature in pregnant women and one study in non-pregnant adults, recommended against supplementation with calcium until the effects of long-term LMWH on bone are examined for different doses and in other non-pregnant populations. Lastly, a few studies have examined the effects of novel anticoagulants on bone. For example, in vitro studies found that rivaroxaban, an oral factor-Xa inhibitor, reduced osteoblast function in a similar way as enoxaparin, while this effect was not shown for fondaparinux, a parenteral factor Xa inhibitor. $^{1,81}$

\section{Future Studies}

The lack of solid evidence on the long-term effects of LMWH on bone in non-pregnant adults suggests a need for future prospective studies. Not only is this patient population heterogeneous, but it is also susceptible to osteoporosis and fractures. ${ }^{35-37}$ For instance, breast cancer and prostate cancer patients face an increased risk of secondary osteoporosis resulting from the use of aromatase inhibitors and androgen deprivation therapy. ${ }^{37}$ As we extend the anticoagulation armamentarium to include novel agents, future studies should assess the effects of these therapies on bone as some were shown to adversely affect bone. ${ }^{81}$ Also, future phase IV or postmarketing surveillance studies should examine this potential but uncommon drug side effect. One way to improve the detection of asymptomatic (morphometric) vertebral fractures can be to use lateral spine X-rays or vertebral fracture assessment (VFA) by DXA to detect subclinical vertebral fractures.

\section{CONCLUSION}

Our systematic review and meta-analysis showed that the use of LMWH for 3-6 months did not increase the risk of fractures compared to UFH or VKA, but longer exposure for up to 24 months was associated with a decrease in BMD. These findings should be interpreted with caution because the current evidence is limited. Future well-designed studies should corroborate whether there are negative effects of long-term LMWH treatment on BMD and fractures in non-pregnant adults. While awaiting better evidence, clinicians should consider monitoring BMD and optimizing vitamin $\mathrm{D}$ and calcium intakes in adults on long-term LMWH who are at increased risk of bone loss or fractures.

Acknowledgments: We thank the four anonymous reviewers and editors for taking the time to review our paper and for providing clinically and methodologically thoughtful comments. We thank Mrs. Elizabeth Uleryk, Hospital Library and Archives, the Hospital for Sick Children, for assisting in developing the search strategies. Dr. GajicVeljanoski was supported by the Johnson Fellowship at University 
Health Network, Dr. Phua by a clinical hematology fellowship at University of Toronto, Dr. Shah by an Applied Research Chair in Reproductive Health and Policy Services Research Award from the Canadian Institutes of Health Research and Dr. Cheung by a Senior Investigator Award from the Canadian Institutes of Health Research/ Institute of Gender and Health.

This work was not funded by grants from any external agency or pharmaceutical company. It was presented at the 2014 American Society for Bone and Mineral Research annual scientific meeting (Houston, Texas).

Corresponding Author: Angela M. Cheung, MD,PhD; Department of MedicineUniversity of Toronto, Toronto, Ontario, Canada (e-mail: angela.m.cheung@gmail.com).

\section{Compliance with ethical standards:}

Conflict of interest disclosures: The authors declare that they do not have a conflict of interest.

Funding source: None

\section{REFERENCES}

1. Garcia DA, Baglin TP, Weitz JI, Samama MM. Parenteral anticoagulants: Antithrombotic Therapy and Prevention of Thrombosis, 9th ed: American College of Chest Physicians Evidence-Based Clinical Practice Guidelines. Chest. 2012;141:e24S-43.

2. Geerts WH, Heit JA, Clagett GP, et al. Prevention of venous thromboembolism. Chest. 2001;119:132S-75.

3. Gould MK, Garcia DA, Wren SM, et al. Prevention of VTE in nonorthopedic surgical patients: Antithrombotic Therapy and Prevention of Thrombosis, 9th ed: American College of Chest Physicians Evidence-Based Clinical Practice Guidelines. Chest. 2012;141:e227S-77.

4. Guyatt GH, Ak1 EA, Crowther M, Gutterman DD, Schuunemann HJ. Executive summary: Antithrombotic Therapy and Prevention of Thrombosis, 9th ed: American College of Chest Physicians EvidenceBased Clinical Practice Guidelines. Chest. 2012;141:7S-47.

5. Hirsh J, Warkentin TE, Shaughnessy SG, et al. Heparin and lowmolecular-weight heparin: mechanisms of action, pharmacokinetics, dosing, monitoring, efficacy, and safety. Chest. 2001;119:64S-94.

6. Lyman GH, Khorana AA, Falanga A, et al. American Society of Clinical Oncology guideline: recommendations for venous thromboembolism prophylaxis and treatment in patients with cancer. J Clin Oncol. 2007;25:5490-505.

7. Wells PS, Forgie MA, Rodger MA. Treatment of venous thromboembolism. JAMA. 2014;311:717-28.

8. Fareed J, Hoppensteadt DA, Fareed D, et al. Survival of heparins, oral anticoagulants, and aspirin after the year 2010. Semin Thromb Hemost. 2008;34:58-73.

9. Hoffman R, Brenner B. The promise of novel direct oral anticoagulants. Best Pract Res Clin Haematol. 2012;25:351-60.

10. Hyers TM, Agnelli G, Hull RD, et al. Antithrombotic therapy for venous thromboembolic disease. Chest. 2001;119:176S-93.

11. Lee AY. The role of low-molecular-weight heparins in the prevention and treatment of venous thromboembolism in cancer patients. Curr Opin Pulm Med. 2003;9:351-5.

12. Akl EA, Kamath G, Kim SY, et al. Oral anticoagulation for prolonging survival in patients with cancer. Cochrane Database Syst Rev. 2007;2:CD006466.

13. Akl EA, van Doormaal FF, Barba M, et al. Parenteral anticoagulation may prolong the survival of patients with limited small cell lung cancer: a Cochrane systematic review. J Exp Clin Cancer Res. 2008;27:4

14. Lee AY, Levine MN. Venous thromboembolism and cancer: risks and outcomes. Circulation. 2003;107:I17-21.

15. Deitcher SR, Kessler CM, Merli G, Rigas JR, Lyons RM, Fareed J. Secondary prevention of venous thromboembolic events in patients with active cancer: enoxaparin alone versus initial enoxaparin followed by warfarin for a 180-day period. Clin Appl Thromb Hemost. 2006; 12:389-96.

16. Eriksson BI, Bauer KA, Lassen MR, Turpie AG. Fondaparinux compared with enoxaparin for the prevention of venous thromboembolism after hipfracture surgery. N Engl J Med. 2001;345:1298-304.
17. Fisher WD, Agnelli G, George DJ, et al. Extended venous thromboembolism prophylaxis in patients undergoing hip fracture surgery-the SAVEHIP3 study. Bone Joint J. 2013;95:459-66.

18. Husted SE, Ziegler BK, Kher A. Long-term anticoagulant therapy in patients with coronary artery disease. Eur Heart J. 2006;27:913-9.

19. Iorio A, Guercini F, Pini M. Low-molecular-weight heparin for the longterm treatment of symptomatic venous thromboembolism: meta-analysis of the randomized comparisons with oral anticoagulants. $J$ Thromb Haemost. 2003; 1:1906-13.

20. Kher A, Samama MM. Primary and secondary prophylaxis of venous thromboembolism with low-molecular-weight heparins: prolonged thromboprophylaxis, an alternative to vitamin $\mathrm{K}$ antagonists. J Thromb Haemost. 2005;3:473-81.

21. Lapidus LJ, Ponzer S, Elvin A, et al. Prolonged thromboprophylaxis with Dalteparin during immobilization after ankle fracture surgery: a randomized placebo-controlled, double-blind study. Acta Orthop. 2007;78:528-35.

22. Lee AY, Levine MN, Baker RI, et al. Low-molecular-weight heparin versus a coumarin for the prevention of recurrent venous thromboembolism in patients with cancer. N Engl J Med. 2003;349:146-53.

23. Luk C, Wells PS, Anderson D, Kovacs MJ. Extended outpatient therapy with low molecular weight heparin for the treatment of recurrent venous thromboembolism despite warfarin therapy. Am J Med. 2001;111:270-3.

24. Meyer G, Marjanovic Z, Valcke J, et al. Comparison of low-molecularweight heparin and warfarin for the secondary prevention of venous thromboembolism in patients with cancer: a randomized controlled study. Arch Intern Med. 2002;162:1729-35.

25. Samama CM, Lecoules N, Kierzek G, et al. Comparison of fondaparinux with low molecular weight heparin for venous thromboembolism prevention in patients requiring rigid or semi-rigid immobilization for isolated non-surgical below-knee injury. J Thromb Haemost. 2013;11:1833-43.

26. Samama CM, Boubli L, Coloby $\mathbf{P}$, et al. Venous thromboembolism prophylaxis in patients undergoing abdominal or pelvic surgery for cancer-A real-world, prospective, observational French study: PReOBS. Thromb Res. 2014;133:985-92.

27. Santamaria A, Juarez S, Reche A, Gomez-Outes A, Martinez-Gonzalez J, Fontcuberta J. Low-molecular-weight heparin, bemiparin, in the outpatient treatment and secondary prophylaxis of venous thromboembolism in standard clinical practice: the ESFERA Study. Int J Clin Pract. 2006;60:518-25.

28. Sideras K, Schaefer PL, Okuno SH, et al. Low-molecular-weight heparin in patients with advanced cancer: a phase 3 clinical trial. Mayo Clin Proc. 2006;81:758-67.

29. Ensom MH, Stephenson MD. Low-molecular-weight heparins in pregnancy. Pharmacotherapy. 1999; 19:1013-25.

30. Greer IA, Nelson-Piercy C. Low-molecular-weight heparins for thromboprophylaxis and treatment of venous thromboembolism in pregnancy: a systematic review of safety and efficacy. Blood. 2005;106:401-7.

31. Lefkou E, Khamashta M, Hampson G, Hunt BJ. Review: Low-molecularweight heparin-induced osteoporosis and osteoporotic fractures: a myth or an existing entity? Lupus. 2010;19:3-12.

32. Le Templier G, Rodger MA. Heparin-induced osteoporosis and pregnancy. Curr Opin Pulm Med. 2008;14:403-7.

33. Backos M, Rai R, Thomas E, Murphy M, Dore C, Regan L. Bone density changes in pregnant women treated with heparin: a prospective, longitudinal study. Hum Reprod. 1999;14:2876-80.

34. Rodger MA, Hague WM, Kingdom J, et al. Antepartum dalteparin versus no antepartum dalteparin for the prevention of pregnancy complications in pregnant women with thrombophilia (TIPPS): a multinational open-label randomised trial. Lancet. 2014;384:1673-83.

35. Sonawane S, Kasbekar N, Berns JS. The safety of heparins in end-stage renal disease. Semin Dial. 2006; 19:305-10.

36. Compston J. Obesity and bone. Curr Osteoporos Rep. 2013;11:30-5.

37. Coleman RE, Rathbone E, Brown JE. Management of cancer treatmentinduced bone loss. Nat Rev Rheumatol. 2013;9:365-74.

38. Liberati A, Altman DG, Tetzlaff J, et al. The PRISMA statement for reporting systematic reviews and meta-analyses of studies that evaluate health care interventions: explanation and elaboration. PLoS Med. 2009;6, e1000100.

39. Wells G, Shea B, O'Connell D, Peterson J, Welch V, Losos M. The NewcastleOttawa Scale (NOS) for assessing the quality if nonrandomized studies in meta-analyses. Available from: URL:http://www.ohri.ca/programs/clinical_ epidemiology/oxford.asp. Accessed 16 Dec 2015.

40. van Tulder M, Furlan A, Bombardier C, Bouter L. Updated method guidelines for systematic reviews in the Cochrane collaboration back review group. Spine. 2003;28:1290-9. 
41. Sutton AJ, Abrams KR, Jones DR, Sheldon TA, Song F. Methods for MetaAnalysis in Medical Research. Chichester: John Wiley \& Sons, Ltd; 2000.

42. Egger M, Smith GD, Altman DG. Systematic Reviews in Health Care: MetaAnalysis in Context. 2nd ed. London: BMJ Publishing Group; 2001.

43. Higgins JP, Thompson SG, Spiegelhalter DJ. A re-evaluation of random-effects meta-analysis. J R Stat Soc Ser A Stat Soc . 2009; 172:137-59.

44. Higgins JP, Thompson SG, Deeks JJ, Altman DG. Measuring inconsistency in meta-analyses. BMJ. 2003;327:557-60.

45. Egger M, Davey SG, Schneider M, Minder C. Bias in meta-analysis detected by a simple, graphical test. BMJ. 1997;315:629-34.

46. Bernis C. Mineral bone density variation in hemodialysis patients: nonfractioned heparin (NFH) versus low molecular weight heparin (LMWH). Nephrol Dial Transplant. 1997; 12:1789.

47. FRISC II Investigators. Long-term low-molecular-mass heparin in unstable coronary-artery disease: FRISC II prospective randomised multicentre study. Lancet. 1999;354:701-7.

48. Grassman ED, Leya F, Fareed J, et al. A randomized trial of the lowmolecular-weight heparin certoparin to prevent restenosis following coronary angioplasty. J Invasive Cardiol. 2001;13:723-8.

49. Haas SK, Freund M, Heigener D, et al. Low-molecular-weight heparin versus placebo for the prevention of venous thromboembolism in metastatic breast cancer or stage III/IV lung cancer. Clin Appl Thromb Hemost. 2012;18:159-65.

50. Hull RD, Pineo GF, Brant RF, et al. Long-term low-molecular-weight heparin versus usual care in proximal-vein thrombosis patients with cancer. Am J Med. 2006; 119:1062-72.

51. Hull RD, Pineo GF, Brant RF, et al. Self-managed long-term lowmolecular-weight heparin therapy: the balance of benefits and harms. Am J Med. 2007;120:72-82.

52. Hull RD, Pineo GF, Brant R, et al. Home therapy of venous thrombosis with long-term LMWH versus usual care: patient satisfaction and postthrombotic syndrome. Am J Med. 2009;122:762-9.

53. Lai KN, Ho K, Cheung RC, et al. Effect of low molecular weight heparin on bone metabolism and hyperlipidemia in patients on maintenance hemodialysis. Int $\mathrm{J}$ Artif Organs. 2001;24:447-55.

54. Monreal M, Lafoz E, Olive A, del Rio L, Vedia C. Comparison of subcutaneous unfractionated heparin with a low molecular weight heparin (Fragmin) in patients with venous thromboembolism and contraindications to coumarin. Thromb Haemost. 1994;71:7-11.

55. Serra R, Buffone G, De Franciscis A, et al. Skin grafting followed by lowmolecular-weight heparin long-term therapy in chronic venous leg ulcers. Ann Vasc Surg. 2012;26:190-7.

56. Veiga F, Escriba A, Maluenda MP, et al. Low molecular weight heparin (enoxaparin) versus oral anticoagulant therapy (acenocoumarol) in the long-term treatment of deep venous thrombosis in the elderly: a randomized trial. Thromb Haemost. 2000;84:559-64.

57. Grzegorzewska AE, Mlot-Michalska M. Low molecular weight heparins and antiplatelet drugs, and bone mineral density in dialysis patients. Adv Perit Dial. 2008;24:125-31.

58. Monreal M, Olive A, Lafoz E, del Rio L. Heparins, coumarin, and bone density. Lancet. 1991;338:706.

59. Rostoker G, Durand-Zaleski I, Petit-Phar M, et al. Prevention of thrombotic complications of the nephrotic syndrome by the lowmolecular-weight heparin enoxaparin. Nephron. 1995;69:20-8.

60. Wawrzynska L, Przedlacki J, Hajduk B, Bielska FH, Tomkowski W, Torbicki A. Low-molecular-weight heparins, acenocoumarol and bone density. Haemostasis. 2001;31:69-70.

61. Wawrzynska L, Tomkowski WZ, Przedlacki J, Hajduk B, Torbicki A Changes in bone density during long-term administration of low- molecular-weight heparins or acenocoumarol for secondary prophylaxis of venous thromboembolism. Pathophysiol Haemost Thromb. 2003;33:64-7.

62. Bauer DC, Schwartz A, Palermo L, et al. Fracture prediction after discontinuation of 4 to 5 years of alendronate therapy: The FLEX Study. JAMA Intern Med. 2014;174:1126-34.

63. National Osteoporosis Foundation. Clinician's Guide to Prevention and Treatment of Osteoporosis. Washington, DC: National Osteoporosis Foundation; 2014.

64. Papaioannou A, Morin S, Cheung AM, et al. 2010 clinical practice guidelines for the diagnosis and management of osteoporosis in Canada: summary. CMAJ. 2010; 182:1864-73.

65. Kanis JA, Johnell O, Oden A, Johansson H, McCloskey E. FRAX and the assessment of fracture probability in men and women from the UK. Osteoporos Int. 2008;19:385-97.

66. Kanis JA, Johansson H, Oden A, Dawson-Hughes B, Melton LJ III, McCloskey EV. The effects of a FRAX revision for the USA. Osteoporos Int. 2010;21:35-40.

67. World Health Organization Collaborating Centre for Metabolic Bone Diseases. FRAX ${ }^{\circledR}$ WHO Fracture Risk Assessment Tool. Available from: URL:http://www.shef.ac.uk/FRAX/tool.aspx?country=9. Accessed 16 Dec 2015.

68. Ioannidis JP. Adverse events in randomized trials: neglected, restricted, distorted, and silenced. Arch Intern Med. 2009;169:1737-9.

69. Zorzela L, Golder S, Liu Y, et al. Quality of reporting in systematic reviews of adverse events: systematic review. BMJ. 2014;348:f7668.

70. Cauley JA, Hochberg MC, Lui LY, et al. Long-term risk of incident vertebral fractures. JAMA. 2007;298:2761-7.

71. Cooper C. The crippling consequences of fractures and their impact on quality of life. Am J Med. 1997;103:12S-7.

72. Kunz R, Oxman AD. The unpredictability paradox: review of empirical comparisons of randomised and non-randomised clinical trials. BMJ. 1998;317:1185-90.

73. Grimes DA, Schulz KF. Bias and causal associations in observational research. Lancet. 2002;359:248-52.

74. Muir JM, Hirsh J, Weitz JI, Andrew M, Young E, Shaughnessy SG. A histomorphometric comparison of the effects of heparin and lowmolecular-weight heparin on cancellous bone in rats. Blood. 1997;89:3236-42.

75. Nishiyama M, Itoh F, Ujiie A. Low-molecular-weight heparin (dalteparin) demonstrated a weaker effect on rat bone metabolism compared with heparin. Jpn J Pharmacol. 1997;74:59-68.

76. Caraballo PJ, Gabriel SE, Castro MR, Atkinson EJ, Melton LJ III. Changes in bone density after exposure to oral anticoagulants: a meta-analysis. Osteoporos Int. 1999;9:441-8.

77. Caraballo PJ, Heit JA, Atkinson EJ, et al. Long-term use of ora anticoagulants and the risk of fracture. Arch Intern Med. 1999;159:1750-6.

78. Matzsch T, Bergqvist D, Hedner U, Nilsson B, Ostergaard P. Effects of low molecular weight heparin and unfragmented heparin on induction of osteoporosis in rats. Thromb Haemost. 1990;63:505-9.

79. Folwarczna J, Janiec W, Sliwinski L. Effects of heparin and lowmolecular-weight heparins on bone mechanical properties in rats. Thromb Haemost. 2004;92:940-6.

80. Baglin T, Barrowcliffe TW, Cohen A, Greaves M. Guidelines on the use and monitoring of heparin. Br J Haematol. 2006; 133:19-34.

81. Solayar GN, Walsh PM, Mulhall KJ. The effect of a new direct Factor Xa inhibitor on human osteoblasts: an in-vitro study comparing the effect of rivaroxaban with enoxaparin. BMC Musculoskelet Disord. 2011:12:247. 